\title{
Institutional Model of Drivers of Digital Development of Human Capital in the Strategic Perspective
}

\author{
Kelchevskaya N.R. ${ }^{1}$ Shirinkina E.V.,"* \\ ${ }^{1}$ Ural Federal University Named After the First President of Russia B.N. Yeltsin, Yekaterinburg, Russia \\ ${ }^{2}$ Surgut State University, Lenin street 1, 628412, Surgut, Russia \\ *Corresponding author. Email: shirinkina86@yandex.ru
}

\begin{abstract}
The relevance of this research is due to the fact that the development of digital technologies provokes the formation of digital skills and, as a result, increases the potential of digital development of human capital. In the context of the development of the digital economy, enterprises are faced with the issue of forming a business strategy in the direction of increasing the level of digitalization and the vector of digital development of human capital. The article reveals the problems faced by enterprises in the organization of business processes. In this regard, the purpose of this research is to form an institutional model of drivers of digital development of human capital in a strategic perspective, which allows us to consider the process of digital development of human capital as the integration of interaction between all participants: the labor market, industry and the education system. The subject of the research is the analysis of the main trends in the development of the digital economy, which allows us to prioritize the digital development of human capital in a different way. A new category "drivers of digital human capital development"is being introduced. The article presents an analysis of digitalization trends in business processes and training and aims to form an understanding of the need to proactively create a digital environment caused by deep changes in the economy and society. In the article, the authors analyze global challenges in the paradigm of digitalization of industries and education in the conditions of rapid development of the digital world. The empirical base is based on materials from leading consulting and IT-companies, global associations and other active participants in the global educational environment. The presented institutional model of drivers of digital development of human capital will transform the approach to strategic management of human capital in the digital economy.
\end{abstract}

Keywords: human capital, digital economy, trends, drivers of development, institutional model

\section{INTRODUCTION}

The relevance of the research is due to the fact that digitalization is considered as a catalyst for the development of business innovations. It brings many opportunities, but also creates new challenges [9].in particular, companies need to understand how to use digitalization tools to increase productivity and how to develop human capital in a digital environment, and this is the focus of theoretical and practical research $[3,8]$.

Digitalization is a factor of competitiveness of enterprises, thanks to which they manage to reduce costs by up to $25 \%$ [4]. therefore, in the conditions of international competition, industrial companies need to actively implement digital technologies and, as a result, new approaches to human capital management from the perspective of developing organizational digital culture and digital knowledge [1,2].

It is obvious that when planning an effective strategy for managing human capital in the context of digitalization of business processes, it is necessary to integrate structural and social components. In this regard, we will analyze the main trends in the development of the digital economy, which allows us to prioritize the digital development of human capital in a different way.

\section{BACKGROUND}

The triumphal march of new technologies in the digital economy and revolutionary scientific discoveries in various fields is steadily gaining momentum [5]. The digitalization level of industries is shown in Fig. 1. 


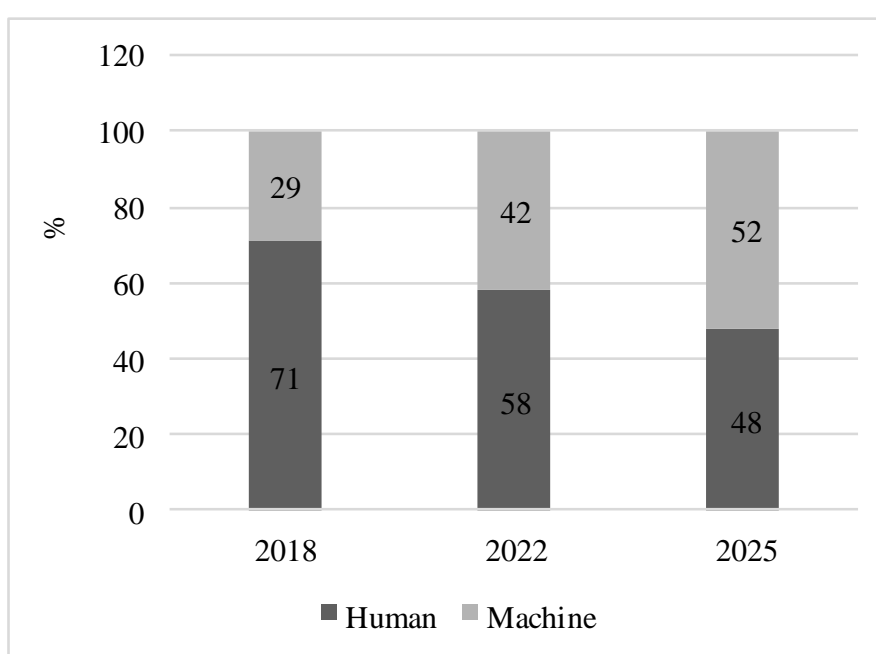

Figure 1 The digitalization level of industries in $\%$ of the ratio of working hours $[10,11]$

However, no one can predict all directions of the future application of breakthrough technologies, and in 2025 the created value can significantly exceed our current estimates.

In Figure 2 presents an assessment of the economic effect that can be achieved by 2025 through the application of each technology in individual industries.

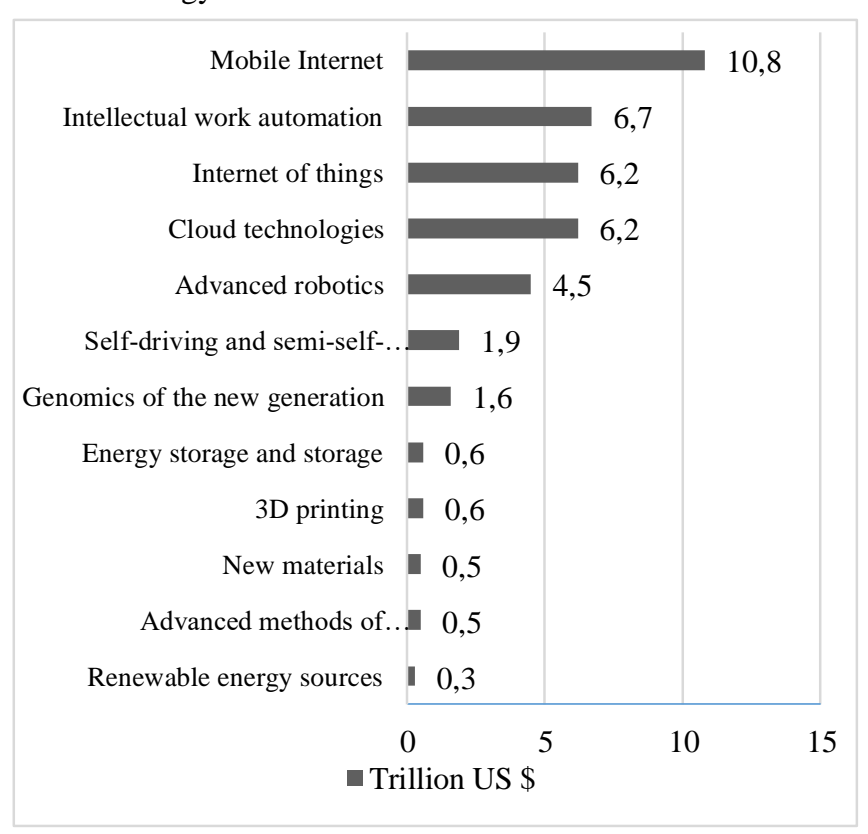

Figure 2 The structure of digital technologies in the context of the predicted economic effect per year by 2025 $[4,10,11]$

According to estimates by the Organization for Economic Co-operation and Development (OECD), over the next $10-20$ years, $14 \%$ of jobs will be fully or partially automated, and another $32 \%$ will undergo significant changes. Business processes need to adapt to these changes. This is possible using the latest technologies that can significantly improve the quality of management decisions. According to the Smoothwall study, $96 \%$ of respondents note the positive impact of technology on the involvement of enterprises in the digitalization of business processes. The global education spending market is currently valued at more than $\$ 5$ trillion and could reach $\$$ 10 trillion by 2030. Despite the volume of total investment, the share of digital solutions in education is only $2 \%$.

Researchers from Reach Capital summed up the results of 2017 and identified the most noticeable trends in the educational technology market in the United States. Firstly, at the moment, more than $94 \%$ of schools are connected to the Internet, however, according to research results, only $22 \%$ of them have sufficient bandwidth to cope with the streaming requirements of training 1:1 (1 device per student). Secondly, the volume of laptops and tablets delivered to educational institutions has increased, thereby getting closer to the goal when each student will have their own computer. There are currently 20 million Google Chromebooks per 50 million students in US public schools, not including tablets provided by Apple and Microsoft. Thirdly, there is a significant decline in traditional publications. This is due to the fact that more and more people prefer electronic / online books over paper. Over the past three years, the S\&P index has grown by $24 \%$, but the index of publishers Pearson and Houghton Mifflin Harcourt has decreased by $58 \%$ and $32 \%$, respectively. Their slow transition to digital equipment cost them a significant market share, as more budgetary digital solutions are rapidly gaining popularity. It is expected that these indicators will only grow, and soon marketing platforms such as TeachersPayTeachers and Nearpod will increasingly become a place for educational content, and traditional publications will cease to be in demand.

For the digital development of human capital is not enough once to gain knowledge or develop skills, it is necessary to regularly update the acquired luggage. The category "digital personnel" was first introduced by the international company in the field of management consulting McKinsey \& Company in July 2017 in its study "Digital Russia: a new reality" [4].

For this purpose, the countries of the upper development trajectory are introducing solutions that stimulate people's lifelong learning - within the educational system, on the basis of employers or on their own. Attempts to discuss this agenda in Russia have not yet led to success. Today in the country there is no systematic solution for updating competencies throughout life. Most people study with graduation from graduation, no later than 25 years old (Fig. 3). 


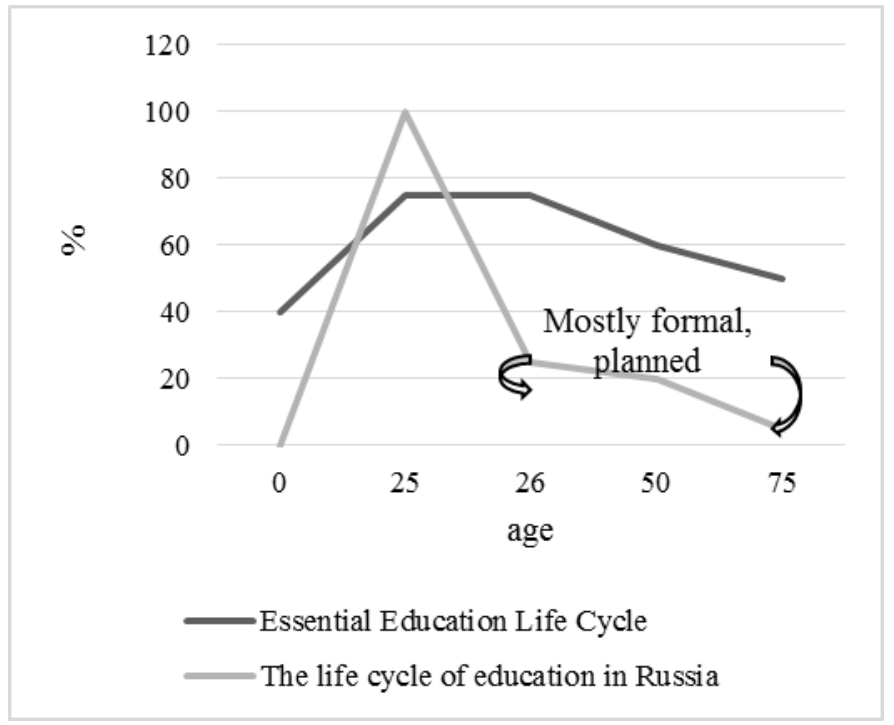

Figure 3 The life cycle of education in Russia [4,6,7]

Training in the course of work is often represented either by formal advanced training, in which there is no real development and updating of skills, or by the precise closure of gaps in the education system. Nevertheless, on average in Russia, the costs of employers to train employees are 10 times less than in Europe. In educational programs in our country, $15 \%$ of the working population and $1 \%$ of pensioners participate - for comparison, in developed countries this is 40 and $5 \%$, respectively. A significant part of the world's population over the age of 25 considers the main part of their educational cycle completed and is not ready to make significant efforts to increase the educational qualification and / or update the package of relevant skills.

At the end of 2017, by the order of the Ministry of Education and Science, a sociological study was conducted to study the attitude of Russians to projects in the field of online learning. The sample involved 1055 people from 15 cities of Russia, representing commercial organizations (heads of companies, training centers and HR directors) and universities (managers, teachers, students) (Fig. 4).

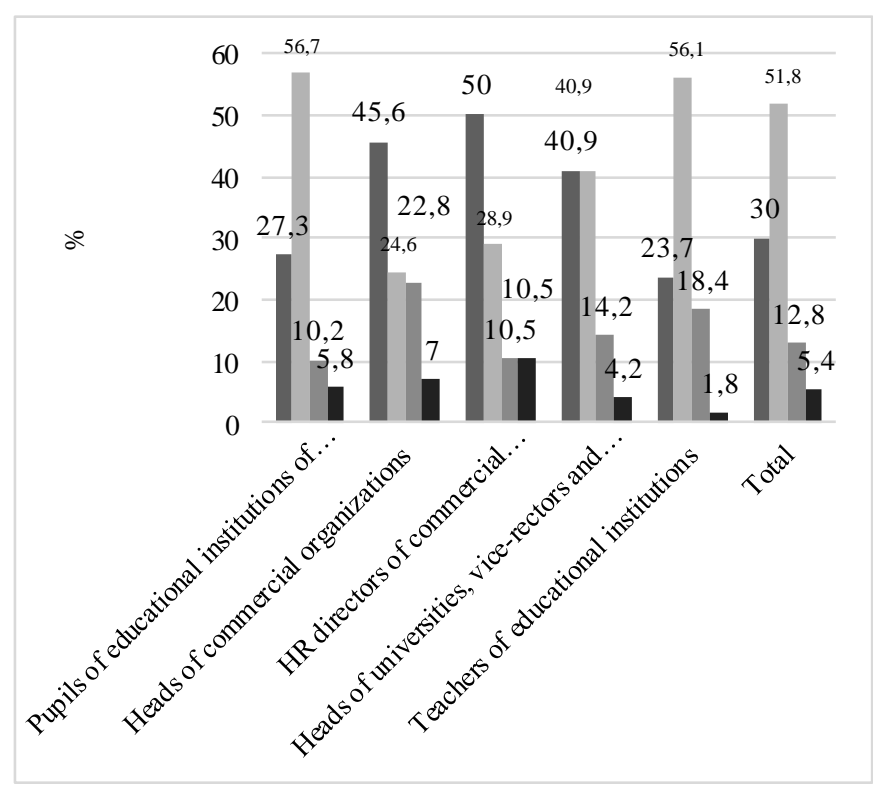

Figure 4 Attitude to the idea of obtaining online education among different target groups, \% of respondents [6].

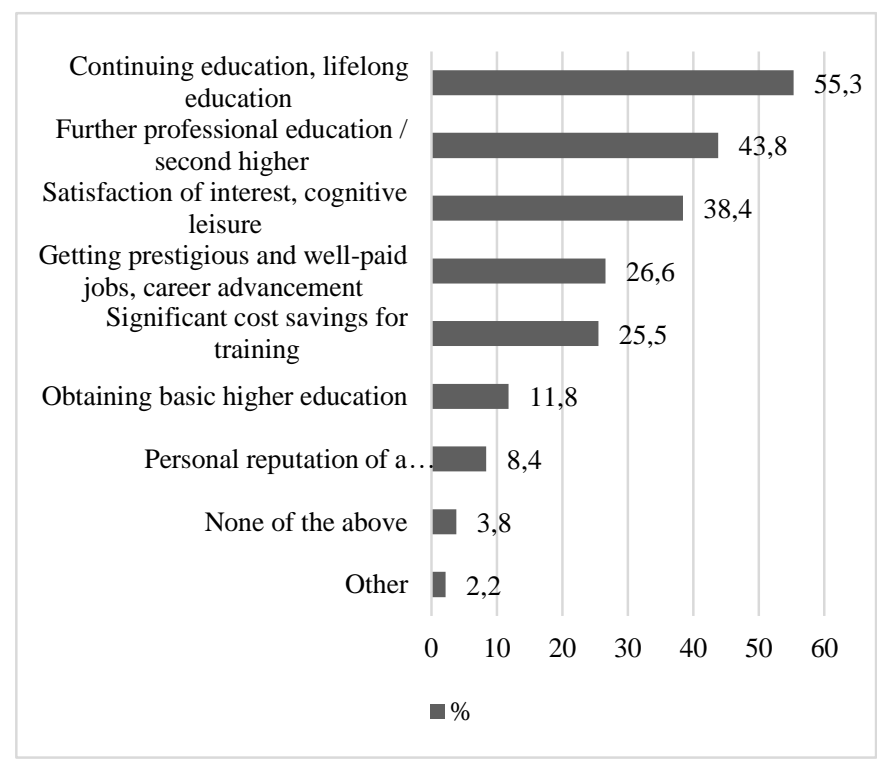

Figure 5 Incentives for the use of digital learning technologies, \% of respondents [6]

The majority of respondents $(51.8 \%)$ are positive about online education. At the same time, online training received the most approval from business representatives (45.6\% of managers and $50 \%$ of HR directors). Heads of training centers and teachers see both advantages and disadvantages in online education (40.9\% of leaders and $56.1 \%$ of teachers, respectively). Students also share the position of teachers (57.6\% of respondents).

Nevertheless, the majority of respondents positively evaluate Russian educational projects, such as the "National Platform for Open Education" and "The Modern 
Digital Educational Environment in the Russian Federation". The implementation of these platforms is approved by $52 \%$ of respondents (Fig. 5).

Among the attractiveness factors of digital learning, respondents cited continuing education (55.3\%), additional professional education or a second higher education (43.8\%). In addition to continuing education, university professors have a factor of satisfying interest and cognitive leisure $(36.4 \%)$.

An analysis of the effectiveness of the use of digital technologies in training has led to ambiguous conclusions. On the one hand, digitalization simplifies the process of interaction between students, both in the classroom and during homework. On the other hand, with the unlimited use of technology, students run the risk of losing their motivation to learn faster and becoming dependent on the technology itself. In particular, the researchers identified social networks, interactive and collaborative platforms as the most risky educational decisions.

To reflect the essence of this form, we introduce a new category "drivers of digital development of human capital". The author's approach to the definition of this concept is as follows: Drivers for the digital development of human capital (from the English "driver" literally "driver", "directing movement") - the development of human capital in the direction of increasing digitalization and digital competence, based on new methods of measuring human capital with using digital technology and artificial intelligence.

The institutional model of drivers for the digital development of human capital in a strategic perspective is presented in Fig. 6.

The institutional model of digital drivers of human capital development in a strategic perspective allows us to consider the process of digital development of human capital as an integration of interaction of all participants: labour market, emerging market environment necessary to motivate people to choose a highly qualified professions; industry, shaping the technological environment of the education system, form educational environment for creating high-quality human capital with the required target competences; health and social security systems that form the social environment for the functioning and digital development of human capital. In accordance with the institutional model of drivers of digital development of human capital in the strategic perspective, the normal functioning of this process is determined by the rationality and systemicity of the structure, which is manifested in the influence of a combination of all external factors. Includes:

1. Drivers to stimulate massive demand for digital knowledge and skills. Drivers to stimulate massive demand for digital knowledge and skills include:

- digital development of industry and all sectors of the economy;

- development in the field of automation, artificial intelligence and digital business models.

- change in the requirements for the employee and working conditions from clearly defined work responsibilities to design work;

- change in the structure of employment;

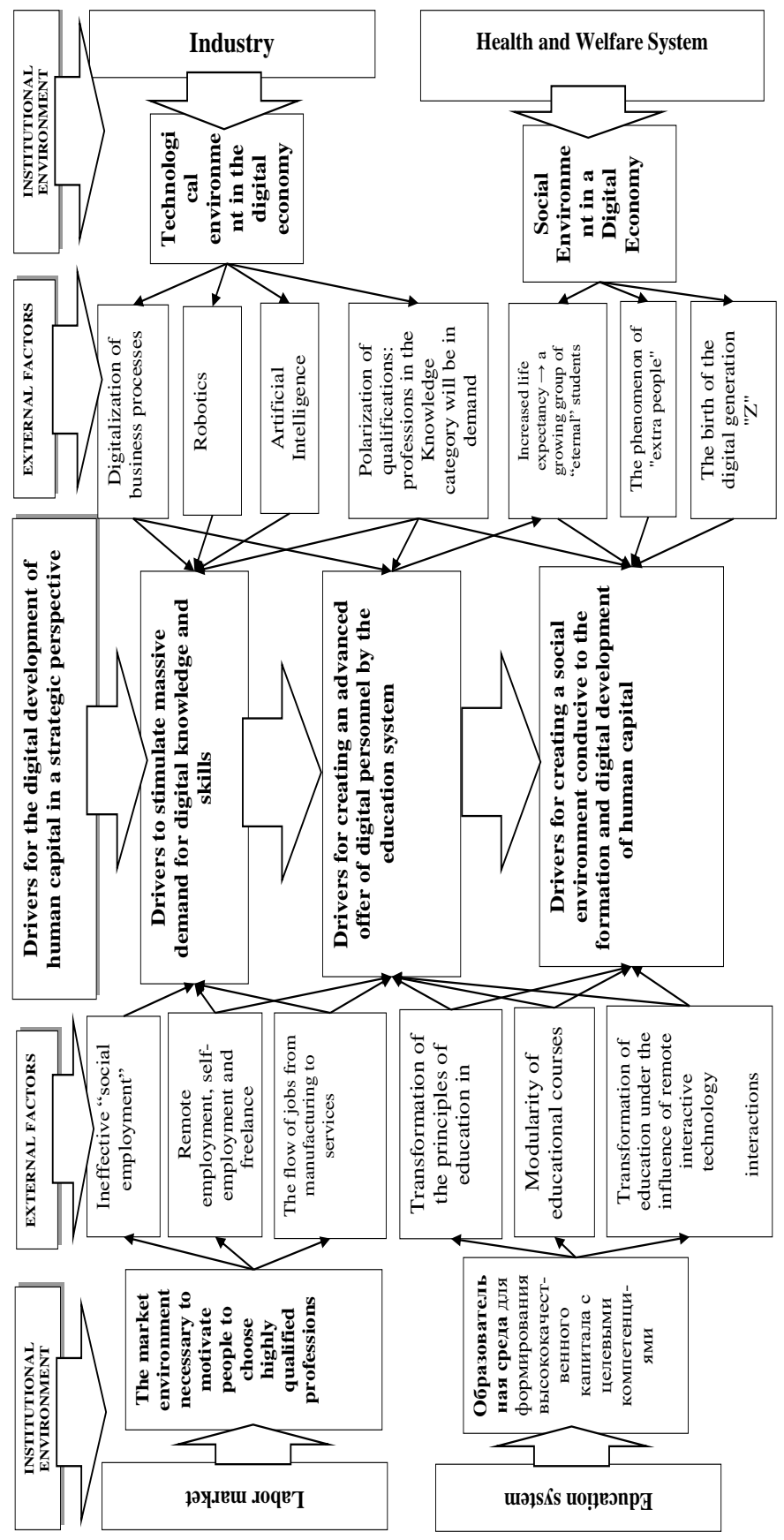

Figure 6 Institutional model of drivers for the digital development of human capital in a strategic perspective. Compiled by the author

- change in the workplace with an increase in the share of labor associated with the development of automated systems;

- the formation of a growing need for the development of digital skills.

2. Drivers for creating an advanced offer of digital personnel by the education system. Drivers for creating an advanced digital cadre offer by the education system include: 


\section{REFERENCES}

large-scale transformation of the Russian education education;

- the development of digital personnel through the improvement of platforms for the interaction of students and potential employers;

- introduction of new approaches to learning and ensuring a high level of basic digital literacy of the population.

3. Drivers for creating a social environment conducive to the formation and digital development of human capital. Drivers for creating a social environment conducive to the formation and digital development of human capital include:

- development of a network society and the distribution of blockchain-based solutions;

- The development of coworking, car sharing and crowdfunding, as integral attributes of the digital economy;

- A change in the structure of educational needs, since digitalization helps to increase life expectancy, and this process will require new approaches to a growing group of "eternal" students.

In order for the drivers of digital development of human capital to work in a strategic perspective, a purposeful systematic impact of all subjects of management and investment in human capital, namely the education system, enterprises, and the state, is necessary. The desired goal can be achieved only if all the subjects of the institutional model presented are ahead of the curve and develop response measures in a strategic perspective.

The presented institutional model of drivers for the digital development of human capital will allow transforming the approach to the strategic management of human capital in the digital economy.

\section{CONCLUSION}

1. Trends in technology have been identified in the context of the development of the digital economy in order to identify new drivers in the development of human capital. 2. A new category "drivers of digital development of human capital" is introduced.

3. An institutional model of drivers for the digital development of human capital in a strategic perspective is presented, which allows us to consider the process of digital development of human capital as an integration of the interaction of all participants: the labor market, industry and the education system

4. The drivers of stimulating mass demand for digital knowledge and skills are identified.

5. The drivers for creating an advanced offer of digital personnel by the education system are identified.

7. The drivers of creating a social environment conducive to the formation and digital development of the human are identified.

8. The presented institutional model of drivers for the digital development of human capital will transform the approach to strategic management of human capital in the digital economy.
[1] V. Mau, "Human capital: challenges for Russia": Economics, vol. 7, 2012, pp. 115.

[2] D. Aboody, B. Lev, Information asymmetry, R\&D, and insider gains, The journal of Finance, vol. 6 (55), 2000, pp. 2747-2766.

[3] G. Akerlof, The Market for 'Lemons': Quality Uncertainty and the Market Mechanism, Journal of Economics, vol. 84 (3), 1970, pp. 488-500.

[4] McKinsey, Digital Economy: A New Reality, 2017, URL:

https://www.mckinsey.com/ru/ /media/McKinsey/Loca tions/Europe $\% 20$ and\%20Middle\%20East/Russia/Our\%20Insights/Digita 1\%20Russia/DigitalRussia-report.ashx

[5] United Nations, World Population Prospects, 2017, URL: https://population.un.org/wpp/DataQuery/

[6] Atlas of new professions, Retired professions, 2015. URL: http://atlas100.ru/future/articles/professiipensionery/

[7] J. Rasmussen, Model of human behavior, 1983. URL: https://lektsia.com/4x4631.html

[8] N.R Kelchevskaya., E.V. Shirinkina, N.I. Strih, Evaluation of Digital Development of Human Capital of Enterprises, 2nd International Conference on Education Science and Social Development (ESSD 2019). - Advances in Social Science, Education and Humanities Research, vol. 298, pp. 446-449.

[9] BCG, Russia 2025: from personnel to talents, 2017, URL: http://d-russia.ru/wpcontent/uploads/2017/11/Skills_Outline_web_tcm26175469.pdf

[10] Global Education Futures, Educational ecosystems for societal transformation, 2018, URL: https://www.edu2035.org/files/GEF\%20Vision\%20Edu cational $\% 20$

Ecosystems\%20for\%20Societal\%20Transformation.pdf

[11] G. Kane, D. Palmer, A. Phillips, D. Kiron, N. Buckley, Aligning the Organization for Its Digital Future, Research report, vol. 5 (81), 2016, pp. 1476. 